\title{
Antioxidant and Antidiabetic Activities of Methanolic extract of Bark of Cinnamomum zeylanicum in Diabetic Rats
}

\author{
Rasvin Singh ${ }^{1}$, Subramani Parasuraman ${ }^{2, *}$, Sathasivam Kathiresan ${ }^{1}$
}

\section{Rasvin Singh ${ }^{1}$, Subramani Parasuraman ${ }^{2, *}$, Sathasivam Kathiresan ${ }^{1}$}

\author{
'Department of Biotechnology, Faculty of \\ Applied Sciences, AIMST University, Kedah, \\ MALAYSIA. \\ ${ }^{2}$ Department of Pharmacology, Faculty of \\ Pharmacy, AIMST University, Kedah, \\ MALAYSIA.
}

\section{Correspondence}

\section{Dr. Subramani Parasuraman}

Department of Pharmacology, Faculty of Pharmacy, AIMST University, Bukit Air Nasi-08100 Bedong, Kedah, MALAYSIA.

Phone no: +60 108826480

E-mail: parasuraman@aimst.edu.my

History

- Submission Date: 28-04-2020;

- Review completed: 18-05-20;

- Accepted Date: 26-06-2020.

DOI : 10.5530/fra.2020.1.4

Article Available online

http://www.antiox.org

\section{Copyright}

() 2020 Phcog.Net. This is an openaccess article distributed under the terms of the Creative Commons Attribution 4.0 International license.

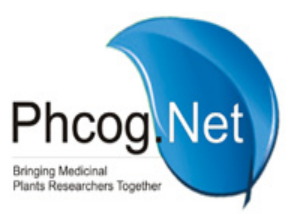

\begin{abstract}
Background: Cinnamomum zeylanicum or Ceylon cinnamon is used for the management of dyspepsia, dysmenorrhea, memory loss and tremor. It is also traditionally recommended for the management of diabetes. Further studies are required to explore the antioxidant and antidiabetic activity of various extracts of bark of C. zeylanicum. Hence, the present study is planned to investigate the antioxidant and antidiabetic activities of methanolic extract of barks of $C$. zeylanicum. Methods: Bark of $C$. zeylanicum was extracted with methanol, ethanol and acetone and its antioxidant activity was studied using 2,2-diphenyl-1-picrylhydrazyl (DPPH) and 2,2-azino-bis-3-ethylbenzothiazoline-6-sulfonic acid (ABTS) free radical scavenging assays. Acute toxic effect of methanolic extract of $C$. zeylanicum (MECZ) studied as per the method described in OECD Guideline for testing of chemicals (Test Guideline 423). MECZ was studied for its antidiabetic effect using streptozotocin-induced diabetic rats. Results: In both DPPH and ABTS free radical scavenging assay, methanolic and acetone extracts exhibited free radical scavenging activity, respectively. In acute toxicity testing, MECZ did not show any significant toxic signs up to $2000 \mathrm{mg} / \mathrm{kg}$, hence the antidiabetic activity of MECZ was carried out at the dose levels of 125,250 and $500 \mathrm{mg} / \mathrm{kg}$. MECZ showed antidiabetic activity from $2^{\text {nd }}$ week of the experiment onward. In the biochemical analysis, MECZ treated animals showed significant decreases in the levels of ALP and urea when compared with control. In lipid profile analysis, diabetic animals and diabetic animals treated glibenclamide showed significant increases in the levels of total cholesterol when compared with normal control and MECZ prevented the STZ-induced hyperlipidemia. At the end of the study, diabetic animals and diabetic animals treated with glibenclamide and MECZ showed significant decreases in the level of insulin when compared with the control group. In the histopathological analysis, sections from the liver, pancreas and kidney of the diabetic animals showed mid-to-moderate toxic effects and glibenclamide and MECZ $500 \mathrm{mg} / \mathrm{kg}$ prevented the STZ-induced cellular changes. Conclusion: The MECZ exhibited significant antioxidant and antidiabetic activities.
\end{abstract}

Key words: Diabetes mellitus, Free radicals, Insulin, Streptozotocin.

\section{INTRODUCTION}

Plants and isolated phytochemicals are generally utilized for the counteractive action and treatment of different wellbeing infirmities from time immemorial interest for homegrown medications, natural wellbeing items, nutraceutical, sustenance supplement, homegrown pharmaceuticals and beauty care products are expanding all-inclusive. ${ }^{1}$ There are approximately 5-15\% of the total species of higher plants which have been investigated intensively and these plants are identified as a good source of bioactive compounds. ${ }^{2}$ Plant secondary metabolites such as taxol, lectinan, morphine and reserpine are good therapeutic agents and are incorporated in modern medicine. ${ }^{3}$ Cinnamomum zeylanicum is one of the well-known plant species for its medicinal properties. It is native to Sri Lanka and is a small evergreen tree belonging to the Lauraceae family and was used in Asia long before it became known in Europe. ${ }^{4}$ This family is well known for its aroma and thick bark and has over 2000 species of trees and shrubs. ${ }^{5}$ The Lauraceae family is economically important as it is used extensively in the treatment of various diseases due to its active biological secondary metabolites such as terpenes, flavanoids, polyphenols and alkaloids that have significant antidiabetic, antiinflammatory, antibacterial, antiviral and antifungal activities. ${ }^{6,7}$ The health effects benefited from $C$. zeylanicum have been demonstrated in vivo and in vitro experiments. The leaf and the bark of the cinnamon species have higher commercial value compared to the root which has camphor as its main constituent. ${ }^{4}$ Trans-cinnamaldehyde, eugenol and linalool are the main components of the $C$. zeylanicum bark. ${ }^{8}$ Mesripour et al. demonstrated the antidiabetic effect of aqueous extract C. zeylanicum bark in alloxan-induced diabetic mice and reported

Cite this article: Singh R, Parasuraman S, Kathiresan S. Antioxidant and Antidiabetic Activity of Methanolic extract of Bark of Cinnamomum zeylanicum in Diabetic Rats. Free Radicals and Antioxidants. 2020;10(1):16-23. 
that the aqueous extract C. zeylanicum has ability to reduce the blood glucose levels and also improves memory performance. ${ }^{9}$ The further studies are required to explore the antioxidant and antidiabetic activity of various extracts of bark of C. zeylanicum. Hence the present study is planned to investigate the antioxidant and antidiabetic activities of bark of methanolic extract of bark of C. zeylanicum.

\section{MATERIALS AND METHODS}

\section{Collection and identification of barks of C. zeylanicum}

The cinnamon barks were obtained from Penang Spice Garden, Pulau Pinang and the authenticity of C. zeylanicum species was confirmed by Dr. Deivanai Subramanian, Faculty of Applied Sciences, AIMST University.

\section{Extraction of barks of $C$. zeylanicum}

C. zeylanicum bark was cleaned thoroughly and placed in an oven to be dried. The dried barks were grounded to the powder and placed in an oven at temperature $35^{\circ} \mathrm{C}$ for overnight to ensure maximum moisture was lost. The powered barks of C. zeylanicum was extracted with a hot percolation method. The powdered barks of C. zeylanicum was packed in a thimble and placed in a Soxhlet apparatus and extracted using methanol, ethanol and acetone. The extraction was carried out for $24 \mathrm{~h}$ at about $55^{\circ} \mathrm{C}-80^{\circ} \mathrm{C}$; the extract was filtered through a muslin cloth. The filtrate was concentrated to a dry mass by evaporation under reduced pressure. The extracts of C. zeylanicum were stored in a desiccator at room temperature until further analysis. The percentage yield of methanolic, ethanolic and acetone extract of C. zeylanicum was found to be $\approx 21, \approx 19$ and $\approx 12 \% \mathrm{w} / \mathrm{v}$, respectively.

\section{Phytochemical screening}

Qualitative phytochemical analysis of methanol, ethanol and acetone extracts of C. zeylanicum were carried out to test for the presence of constituents such as alkaloids, flavonoids, terpenoids, saponins, tannins and glycoside. Total flavonoid content and total phenolic content of methanolic, ethanolic and acetone extracts of C. zeylanicum determined by the method described by elsewhere. ${ }^{10-12}$ Total flavonoid content and total phenolic content of various extracts of C. zeylanicum compared with gallic acid and quercetin, respectively. Gallic acid and quercetin were used as standards and the results were expressed as gallic acid equivalents (GAE) and quercetin equivalents $(\mathrm{QE})$. All tests were done in triplicates.

\section{Antioxidant activity}

Antioxidant activity of extracts of C. zeylanicum were determined using 2,2-diphenyl-1-picrylhydrazyl (DPPH) and 2,2-azino-bis-3ethylbenzothiazoline-6-sulfonic acid (ABTS) radical scavenging methods using the method described elsewhere. ${ }^{13,14}$

DPPH free radical scavenging assay: A stock solution of $0.1 \mathrm{mM}$ concentration DPPH was freshly prepared in methanol and kept in the dark at $4^{\circ} \mathrm{C}$. A $2 \mathrm{ml}$ of different concentrations (50, $200,400,600,800$ and $1000 \mu \mathrm{g} / \mathrm{ml}$ ) of plant extracts were added to $1 \mathrm{ml}$ of DPPH stock solution and incubated at room temperature $\left(23-27^{\circ} \mathrm{C}\right)$ in the dark for approximately $20 \mathrm{~min}$. Later, the absorbance was recorded against a blank at $517 \mathrm{~nm}$ using an ultraviolet-visible (UV-vis) spectrophotometer (Model UV 1800, Shimadzu, Japan). All analysis was performed in triplicate. The DPPH free radical scavenging properties of extracts of $C$. zeylanicum was compared with ascorbic acid. Inhibition of DPPH radical in term of percentage (\%) was calculated using the formula [(Ac-As)/Ac $\mathrm{X} 100 ; \mathrm{Ac}=$ Absorbance of control and As = Absorbance of sample].
ABTS free radical scavenging activity: ABTS $(7 \mathrm{mM})$ was mixed with $2.45 \mathrm{mM}$ potassium persulfate to obtain the stock solution of ABTS. Before proceeding with the test, the mixture was left in the dark for $12 \mathrm{hr}$. Before ABTS was added to the sample, the samples had to be diluted to obtain an absorbance of 0.7 at $734 \mathrm{~nm}$. The extracts were then dissolved in absolute ethanol with the concentrations of $100,300,500$, 700, 900 and $1000 \mu \mathrm{g} / \mathrm{ml}$. . Diluted ABTS $(0.5 \mathrm{ml})$ solution was added to the $0.5 \mathrm{ml}$ of sample and left for $8 \mathrm{~min}$ before the absorbance was taken again at $734 \mathrm{~nm}$. All analysis was performed in triplicate. The ABTS free radical scavenging properties of extracts of $C$. zeylanicum was compared with trolox. Inhibition of ABTS radical in term of percentage (\%) was calculated using the formula [(Ac-As)/Ac X 100; Ac = Absorbance of control and As = Absorbance of sample].

\section{Antidiabetic activity}

Animals: Healthy, adult, either gender of Sprague-Dawley (SD) rats (180 \pm 15 g body weight [BW]) were obtained from Shafazz Enterprise, Malaysia. The animals were housed in large, spacious, polyacrylic cages at ambient room temperature with $12 \mathrm{~h}$ light/12 h dark cycle. Rats had free access to water and rodent pellets diet. The study was approved by the Human and Animal Ethics Committee of AIMST University and the study was conducted according to the Animal Research Review Panel Guidelines.

Acute toxicity testing: The healthy, adult, female SD rats were used for acute toxicity testing. The study was carried out according to the guidelines that were set by the Organization for Economic Co-operation and Development (OECD), Test Guideline 423. The rats (3 animals/ dose) were overnight and orally fed with methanolic, ethanolic and acetone extracts of barks of C. zeylanicum in increasing dose of 5, 50, 300 and $2000 \mathrm{mg} / \mathrm{kg} \mathrm{BW}$. The rats were closely monitored for changes in their neurological, behavioral and autonomic profiles for $24 \mathrm{hr}$ upon administration of doses. The animals were observed (at least two times a day) for a period of 14 days for any for toxicity signs. ${ }^{15}$

Antidiabetic activity: In acute toxicity testing methanolic extract of barks of C. zeylanicum (MECZ) did not show any toxic sings. Hence MECZ was used for antidiabetic screening. Healthy, adult, male SD rats were used in this study. Diabetes mellitus was induced in overnightfasted rats by administration of intraperitoneal injection of freshly prepared $55 \mathrm{mg} / \mathrm{kg}$ streptozotocin (STZ) in $0.1 \mathrm{M}$ citrate buffer $(\mathrm{pH}$ 4.5). After $24 \mathrm{hr}$ of STZ administration, the rats were given with glucose solution ( $2 \mathrm{ml} / \mathrm{kg} \mathrm{BW})$ to avoid hypoglycemic mortality. ${ }^{16}$ After $48 \mathrm{hr}$, the blood sample was collected from the tail vein and blood glucose was measured to confirm diabetes mellitus. Rats with fasting blood glucose of $>11 \mathrm{mmol} / \mathrm{L}$ were considered to have diabetes and they were used for this experiment. These diabetic animals were randomly divided into five groups (Group II - VI) as follows $(n=6)$.

- Group I: Normal control

- Group II: Diabetic control

- Group III: Diabetic animals treated with glibenclamide $(20 \mathrm{mg} / \mathrm{kg})$

- Group IV: Diabetic animals treated with MECZ (125 mg/kg)

- Group V: Diabetic animals treated with MECZ (250 mg/kg)

- Group VI: Diabetic animals treated with MECZ (500 mg/kg)

The animals in group I and group II were administered with $0.5 \%$ w/v carboxymethyl cellulose (CMC). Animals in group III were treated with $20 \mathrm{mg} / \mathrm{kg} \mathrm{BW}$ of glibenclamide and animals in group IV - VI was treated with MECZ at dose levels of 125, 250 and $500 \mathrm{mg} / \mathrm{kg}$ BW, respectively. The dose of MECZ was derived from toxicological study. The standard and investigational drugs were suspended in $0.5 \% \mathrm{w} / \mathrm{v} \mathrm{CMC}$ and administered once daily through oral gavage for 21 consecutive days. Few drops of venous blood was collected from the tail vein on the 
$2^{\text {nd }}, 7^{\text {th }}, 14^{\text {th }}$ and $21^{\text {st }}$ day of the experiment and immediately utilized for the estimation of blood glucose (whole blood) using an Blood Glucose Meters (Accu-Chek ${ }^{\odot}$ Active glucose meter, Roche Diagnostics). Throughout the study, body weight changes were monitored at regular intervals. At the end of the study, blood sample was withdrawn from all the experimental animals through retro-orbital plexus puncture and the serum was separated and utilized for biochemical analysis. ${ }^{17}$ Later, the rats were sacrificed and organs such as liver, pancreas, and kidney were collected for histopathological analysis and they were preserved in $10 \% \mathrm{v} / \mathrm{v}$ buffered neutral formalin.

\section{Biochemical analysis}

During the experiment, few drops of venous blood was collected from the tail vein and used for the estimation of blood glucose levels using Blood Glucose Meters. At the end of the study, a few milliliters of the blood sample were collected in a plain glass tube through retro-orbital plexus and the serum separated by centrifuging at 3000 RPM for $20 \mathrm{~min}$. The serum sample was utilized for estimation of biochemical markers such as serum glutamic oxaloacetic transaminase (SGOT), serum glutamic-pyruvic transaminase (SGPT), alkaline phosphatase (ALP), creatinine, urea, total protein, albumin, sodium, chloride and, potassium and lipid profile such as total cholesterol, triglyceride and high-density lipoprotein (HDL) cholesterol using performed using automated biochemistry analyzer (Olympus 640 Biochemistry Analyzer, Tokyo, Japan) at Gribbles Pathology Sdn. Bhd. (Sungai Petani, Kedah, Malaysia). The low-density lipoprotein (LDL) level, Very low-density lipoprotein (VLDL) and TC/HDL ratio were calculated mathematically. ${ }^{17}$ Plasma insulin is Insulin is measured by ELISA method at Gribbles Pathology Sdn. Bhd. (Sungai Petani, Kedah, Malaysia).

\section{Organ weight analysis}

At the end of the study, all the experimental animals were sacrificed under mild ether anesthesia followed by cervical dislocation. The animal was dissected and the gross pathology was observed. The organs such as liver and kidney were harvested and absolute organ weights were measure and relative organ weight was calculated.

\section{Histopathological analysis}

Liver, pancreas, and kidney samples were excised from animals from group I, II, III \& VI, and preserved in $10 \% \mathrm{v} / \mathrm{v}$ buffered neutral formalin. The liver, pancreas, and kidney sample were embedded in paraffin after being dehydrated in alcohol and subsequently cleared with xylene. Liver, pancreas, and kidney sections of thickness $5 \mathrm{~mm}$ were prepared from paraffin blocks, stained with hematoxylin and eosin (H \& E) and mounted in neutral DPX medium. The sections were examined under a light microscope.

\section{Statistical analysis}

The mean \pm standard error of the mean (SEM) values was calculated for each group. Statistical analysis was carried out using One-way ANOVA followed by Tukey's post hoc test. $\mathrm{P}<0.05$ was considered to be significant.

\section{RESULTS}

\section{Phytochemical test}

Phytochemical analysis of methanolic, ethanolic and acetone extracts of C. zeylanicum were showed presence of glycosides, flavonoids, alkaloids, saponins, tannins and terpenoids.

Ethanolic extract of C. zeylanicum exhibits more phenolic content (551.67 mg GAE/g) followed by acetone extract (517 mg GAE/g) and methanolic extract (439.33 mg GAE/g) of C. zeylanicum. In total flavonoid content analysis, acetone extract of C. zeylanicum recorded the highest flavonoid content (634.2 mg QE/g) which was followed by methanolic (142.5 mg $\mathrm{QE} / \mathrm{g}$ ) and ethanolic extract (117.5 mg QE/g) of C. zeylanicum.

\section{Antioxidant activity}

In DPPH free radical scavenging assay, MECZ exhibited the highest scavenging activity when compared against other extracts, recording activity of $94.97 \pm 0.25 \%$ at concentrations of $1000 \mu \mathrm{g} / \mathrm{ml}$ and the results were comparable with the same concentration of ascorbic acid $(95.92 \pm 0.29 \%)$. The acetone and ethanolic extracts of C. zeylanicum had the $92.32 \pm 0.69 \%$ and $87.33 \pm 0.42 \%$ scavenging activity at concentration of $1000 \mu \mathrm{g} / \mathrm{ml}$, respectively. In ABTS free radical scavenging assay, acetone extract of C. zeylanicum exhibited the highest scavenging activity $(94.55 \pm 0.91 \%)$ at concentrations of $1000 \mu \mathrm{g} / \mathrm{ml}$ and the same concentration of Trolox exhibited $64.45 \pm 0.43 \%$ scavenging activity. The methanolic and ethanolic extracts of C. zeylanicum had the $93.14 \pm$ $0.40 \%$ and $75.56 \pm 0.96 \%$ scavenging activity at a concentration of 1000 $\mu \mathrm{g} / \mathrm{ml}$, respectively. Since the MECZ exhibited the highest scavenging activity in DPPH method and relatively more free scavenging activity in the ABTS method, the further antidiabetic study was carried out with MECZ.

\section{Acute toxicity testing}

In acute toxicity testing, methanolic and ethanolic extracts of $C$. zeylanicum did not show any significant toxic effects up to $2000 \mathrm{mg} / \mathrm{kg}$. The animals treated with acetone extract of C. zeylanicum at $2000 \mathrm{mg} / \mathrm{kg}$ showed mortality (one of three animals) on $14^{\text {th }}$ day of the experiment.

\section{Antidiabetic activity}

Effect of MECZ on body weight: Throughout the study, the diabetic animals showed a reduction in body weight when compared with control. But the results were not significant. The animals treated with glibenclamide or MECZ at the dose levels of 125, 250 and $500 \mathrm{mg} / \mathrm{kg}$ did not showed any significant changes in body weight when compared with control (Figure 1).

Effect of MECZ on blood glucose: Throughout the study, diabetic control animals showed a significant increase in blood glucose levels $(P<0.001)$, when compared with normal control. Whereas the diabetic animals treated with glibenclamide or MECZ at the dose levels of 250 $\mathrm{mg} / \mathrm{kg}$ showed significant antidiabetic effect from day 7 onwards when compared with diabetic control. The animals treated with MECZ at 125 and $500 \mathrm{mg} / \mathrm{kg}$ treated animals showed antidiabetic activity from day 14 onwards, when compared with diabetic control (Table 1).

Effect of MECZ on biochemical parameters: Effect of MECZ on biochemical parameters were summarized in Table 2. The animals treated with glibenclamide or MECZ did not show any significant changes

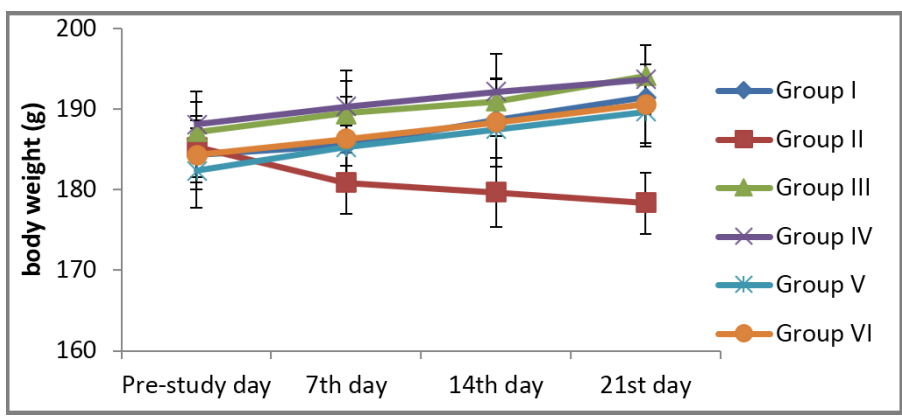

Figure 1: Effects of methanolic extract of barks $C$. zeylanicum on body weight of SD rats. Values are expressed as mean $\pm \operatorname{SEM}(n=6)$. 
in the levels of SGOT, SGPT, total protein and total bilirubin when compared with control. The animals treated with glibenclamide showed a significant increase in the levels of urea and MECZ showed significant decreases in the levels of ALP (at 250 and $500 \mathrm{mg} / \mathrm{kg}$ dose levels) and urea (at $250 \mathrm{mg} / \mathrm{kg}$ ) when compared with control. The animals treated with MECZ showed significant decreases in the levels of ALP and urea when compared with control, but the values are within normal limits.

Table 1: Effects of methanolic extract of barks C. zeylanicum on blood glucose levels of SD rats.

\begin{tabular}{|c|c|c|c|c|}
\hline \multirow{2}{*}{ Group } & \multicolumn{4}{|c|}{ Blood glucose (mmol/L) } \\
\hline & $0^{\text {th }}$ day & $7^{\text {th }}$ day & $14^{\text {th }}$ day & $21^{\text {st }}$ day \\
\hline Group I & $5.80 \pm 0.27$ & $6.07 \pm 0.27$ & $5.78 \pm 0.37$ & $5.87 \pm 0.41$ \\
\hline Group II & $\begin{array}{l}11.53 \pm \\
0.52^{* * *}\end{array}$ & $\begin{array}{l}12.37 \pm \\
0.62^{* * *}\end{array}$ & $\begin{array}{l}13.07 \pm \\
0.70^{* * *}\end{array}$ & $12.93 \pm 0.53^{* * *}$ \\
\hline $\begin{array}{l}\text { Group } \\
\text { III }\end{array}$ & $\begin{array}{l}11.35 \pm \\
0.77^{* * *}\end{array}$ & $9.67 \pm 0.97^{*}$ & $7.25 \pm 0.72^{\# \# \#}$ & $6.62 \pm 0.48^{\# \# \#}$ \\
\hline $\begin{array}{l}\text { Group } \\
\text { IV }\end{array}$ & $\begin{array}{l}12.27 \pm \\
0.72^{* * *}\end{array}$ & $10.15 \pm 0.66^{* *}$ & $9.08 \pm 1.04^{* \# \#}$ & $8.62 \pm 0.55^{\text {*\#\#\# }}$ \\
\hline Group V & $\begin{array}{l}11.93 \pm \\
0.92^{* * *}\end{array}$ & $\begin{array}{c}10.57 \pm \\
0.52^{* * * * \#}\end{array}$ & $7.93 \pm 0.75^{\# \# \#}$ & $7.53 \pm 0.61^{\# \# \#}$ \\
\hline $\begin{array}{l}\text { Group } \\
\text { VI }\end{array}$ & $\begin{array}{l}11.97 \pm \\
0.81^{\star * \star}\end{array}$ & $8.30 \pm 0.86$ & $6.98 \pm 0.50^{\# \# \#}$ & $7.10 \pm 0.81^{\# \# \#}$ \\
\hline
\end{tabular}

Values are expressed as mean $\pm \operatorname{SEM}(n=6) .{ }^{*} P<0.05 ;{ }^{* *} P<0.01$ and ${ }^{* * *} P<0.001$ compare to normal control [group I]; ${ }^{* *} P<0.01$ and ${ }^{\# \# *} P<0.001$ compare to diabetic control [Group II] (One-way ANOVA followed by Tukey's post hoc test).
In electrolyte analysis, the animals treated with MECZ at dose levels of 125 and $500 \mathrm{mg} / \mathrm{kg}$ showed a significant decrease in the level of sodium ion when compared with diabetic control. Also, no significant changes in the levels of chloride and potassium ions were observed (Table 3). At the end of the study, diabetic animals and diabetic animals treated with glibenclamide and MECZ showed significant decreases $(P<0.001)$ in the level of insulin when compared with the control group. Both glibenclamide and MECZ have partially improved insulin levels, but the results were not significant (Table 3 ).

Effect of MECZ on lipid profile: The diabetic animals and diabetic animals treated with glibenclamide showed the significant increases in the levels of total cholesterol when compared with control. Whereas the animals treated with MECZ didn't show any significant changes in the levels of total cholesterol when compared with control. No significant changes in the levels of triglyceride, HDL, LDL, VLDL and TC/HDL ratio were observed with any of the treatment groups when compared with control and diabetic control (Table 4).

Effect of MECZ on organ weight analysis: The diabetic animals and diabetic animals treated with glibenclamide and MECZ didn't show any significant changes in organ weights of liver and kidney when compared with normal control. No significant changes in the organ weights of liver and kidney were observed with glibenclamide and MECZ treated groups when compared with normal and diabetic control.

Effect of MECZ on histology: In histopathological analysis, sections from liver, pancreas and kidney of diabetic control, glibenclamide and MECZ $500 \mathrm{mg} / \mathrm{kg}$ treated animals showed mid-to-moderate toxic effects (Figure 2).

Table 2: Effects of methanolic extract of barks C. zeylanicum on biochemical parameters of SD rats.

$\begin{array}{ccccccccc}\text { Groups } & \text { SGOT (IU/L) } & \begin{array}{c}\text { SGPT } \\ (\mathrm{IU} / \mathrm{L})\end{array} & \text { ALP (IU/L) } & \begin{array}{c}\text { Total } \\ \text { Protein } \\ (\mathbf{g} / \mathrm{L})\end{array} & \begin{array}{c}\text { Albumin } \\ (\mathbf{g} / \mathrm{L})\end{array} & \begin{array}{c}\text { Total } \\ \text { bilirubin } \\ (\mathrm{mg} / \mathrm{dL})\end{array} & \begin{array}{c}\text { Urea }(\mathrm{mg} / \\ \mathrm{dL})\end{array} & \begin{array}{c}\text { Creatinine } \\ (\mathrm{mg} / \mathrm{dL})\end{array} \\ \text { Group I } & 210.67 \pm 8.39 & 80.43 \pm 3.69 & 64 \pm 1.77 & 62.98 \pm 1.45 & 39.5 \pm 1.84 & 1.03 \pm 0.11 & 39.5 \pm 1.03 & 0.65 \pm 0.07 \\ \text { Group II } & 205.67 \pm 5.56 & 81.35 \pm 6.85 & 71.5 \pm 3.74 & 47.43 \pm 2.03 & 36.33 \pm 2.17 & 1.45 \pm 0.15 & 43.85 \pm 1.84 & 0.87 \pm 0.08 \\ \text { Group III } & 227.83 \pm 6.03 & 71.38 \pm 4.94 & 66.5 \pm 4.33 & 64.92 \pm 1.76 & 43.83 \pm 4.7 & 1.23 \pm 0.13 & 31.82 \pm 2.37 & 0.91 \pm 0.07^{*} \\ \text { Group IV } & 204.83 \pm 3.59 & 71.25 \pm 6.21 & 55.33 \pm 3.89 & 61.93 \pm 2.23 & 42.5 \pm 1.41 & 0.88 \pm 0.11 & 29.42 \pm 2.24^{*} & 0.69 \pm 0.04 \\ \text { Group V } & 211.83 \pm 2.80 & 72.67 \pm 3.97 & 48.33 \pm 2.91^{*} & 64.67 \pm 2.73 & 41.33 \pm 1.28 & 0.96 \pm 0.03 & 27.70 \pm 2.00^{* *} & 0.68 \pm 0.05\end{array}$

Values are expressed as mean \pm SEM $(n=6) .{ }^{*} P<0.05 ;{ }^{* *} P<0.01$ and ${ }^{* *} P<0.001$ compare to normal control (One-way ANOVA followed by Tukey's post-hoc test).

Table 3: Effects of methanolic extract of barks C. zeylanicum on biochemical parameters of SD rats.

$\begin{array}{ccccc}\text { Groups } & \text { Sodium }(\mathrm{mmol} / \mathrm{L}) & \text { Chloride }(\mathrm{mmol} / \mathrm{L}) & \text { Potassium }(\mathrm{mmol} / \mathrm{L}) & \text { Insulin }(\mathrm{mU} / \mathrm{L}) \\ \text { Group I } & 146 \pm 4.66 & 73.5 \pm 3.17 & 5 \pm 0.28 & 1.38 \pm 0.14 \\ \text { Group II } & 161.67 \pm 4.94 & 79.83 \pm 3.24 & 5.24 \pm 0.50 & 0.35 \pm 0.14^{* * *} \\ \text { Group III } & 138.83 \pm 4.69 & 68.17 \pm 5.61 & 4.52 \pm 0.29 & 0.52 \pm 0.14^{* * *} \\ \text { Group IV } & 135.67 \pm 5.12 \# & 70.33 \pm 6.59 & 4.93 \pm 0.34 & 0.57 \pm 0.12^{* *} \\ \text { Group V } & 135 \pm 5.86 & 74.5 \pm 4.88 & 5.38 \pm 0.29 & 0.68 \pm 0.14^{* *} \\ \text { Group VI } & 126.5 \pm 4.82 \# & 76.83 \pm 5.00 & 5.07 \pm 0.28 & 0.77 \pm 0.11^{\star}\end{array}$

Values are expressed as mean $\pm \operatorname{SEM}(n=6) .{ }^{*} P<0.05 ;{ }^{* *} P<0.01$ and ${ }^{* *} P<0.001$ compare to normal control; $\# P<0.05$ compare to diabetic control (One-way ANOVA followed by Tukey's post-hoc test). 
Table 4: Effects of methanolic extract of barks C. zeylanicum on lipid profile of SD rats.

$\begin{array}{ccccccc}\text { Groups } & \begin{array}{c}\text { Total cholesterol } \\ (\mathrm{mmol} / \mathrm{L})\end{array} & \begin{array}{c}\text { Triglyceride } \\ (\mathrm{mmol} / \mathrm{L})\end{array} & \mathrm{HDL}(\mathrm{mmol} / \mathrm{L}) & \mathrm{LDL}(\mathrm{mmol} / \mathrm{L}) & \begin{array}{c}\text { VLDL } \\ (\mathrm{mmol} / \mathrm{L})\end{array} & \text { TC/HDL ratio } \\ \text { Group I } & 2.56 \pm 0.09 & 0.89 \pm 0.06 & 0.35 \pm 0.03 & 1.8 \pm 0.1 & 0.36 \pm 0.02 & 7.48 \pm 0.68 \\ \text { Group II } & 3.43 \pm 0.25^{* *} & 1.05 \pm 0.08 & 0.3 \pm 0.04 & 2.68 \pm 0.27 & 0.54 \pm 0.05 & 12.14 \pm 1.57 \\ \text { Group III } & 3.41 \pm 0.22^{*} & 0.98 \pm 0.07 & 0.35 \pm 0.02 & 2.58 \pm 0.23 & 0.52 \pm 0.05 & 10.21 \pm 1.18 \\ \text { Group IV } & 2.78 \pm 0.14 & 0.74 \pm 0.03 & 0.41 \pm 0.03 & 2.03 \pm 0.13 & 0.41 \pm 0.03 & 6.98 \pm 0.6 \\ \text { Group V } & 2.76 \pm 0.1 & 0.77 \pm 0.03 & 0.43 \pm 0.03 & 1.99 \pm 0.11 & 0.4 \pm 0.02 & 6.62 \pm 0.46 \\ \text { Group VI } & 2.57 \pm 0.15 & 0.73 \pm 0.04 & 0.37 \pm 0.02 & 1.86 \pm 0.15 & 0.37 \pm 0.03 & 6.89 \pm 0.16\end{array}$

Values are expressed as mean $\pm \operatorname{SEM}(n=6) .{ }^{*} P<0.05$ and ${ }^{*} P<0.01$ compare to normal control (One-way ANOVA followed by Tukey's post hoc test).
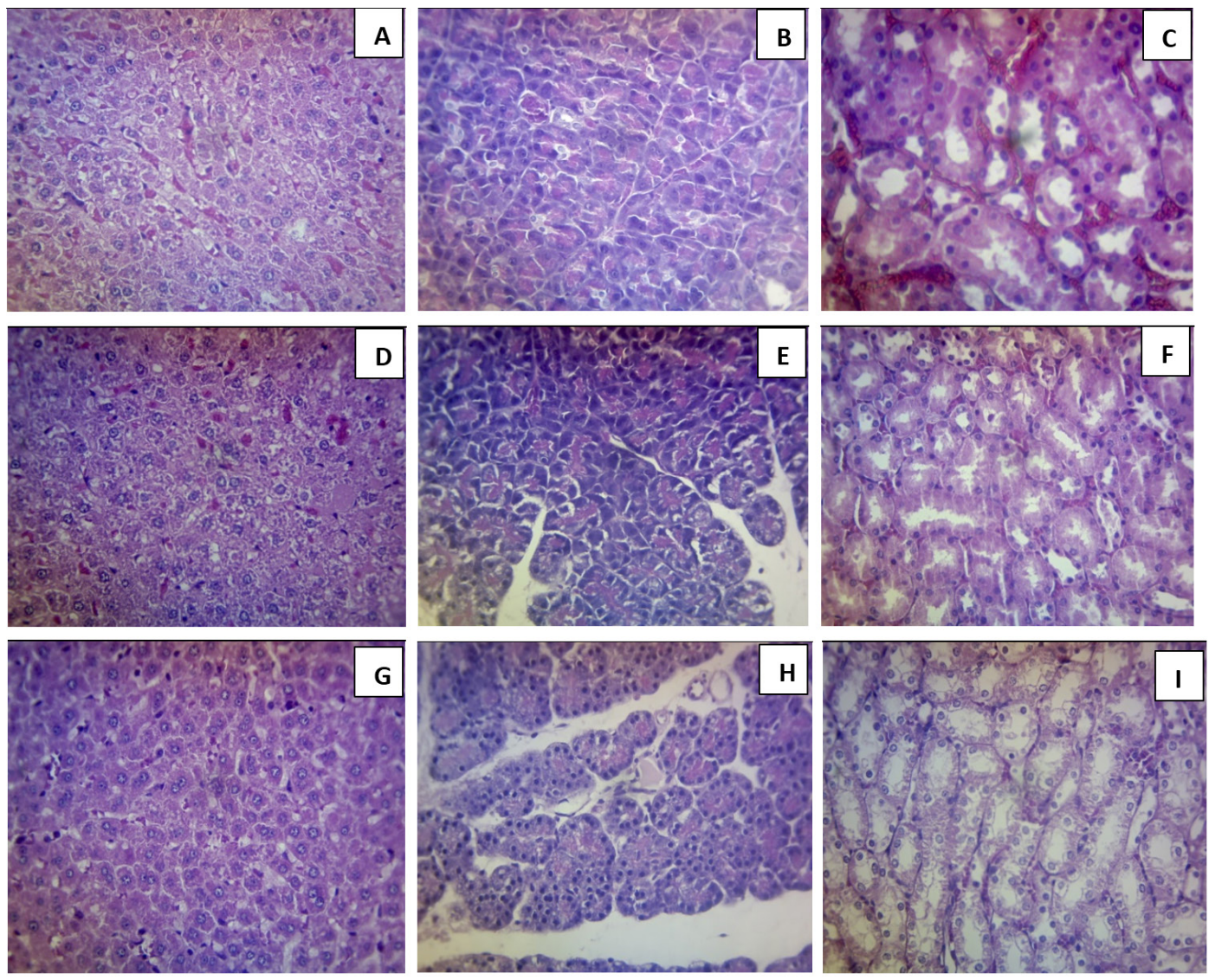

Figure 2: Photomicrograph of a section of organs of diabetic animals and animals treated with glibenclamide and methanolic extract of Cinnamomum zeylanicum $500 \mathrm{mg} / \mathrm{kg}(\mathrm{H} \& \mathrm{E}, \times 400)$. (A) Liver of diabetic rat showing normal configuration of liver lobules with patchy feathery degeneration of hepatocytes; (B) pancreas of diabetic rat showing permanent vesicular nuclei, no evidence of damage to the individual acinar cells and focal toxic changes. (C) kidney of diabetic rat showing congested glomeruli and granular degeneration of the tubular epithelial cells; (D) liver of glibenclamide-treated rat showing congested hepatocytes; (E) pancreas of glibenclamide-treated rat showing fetal pancreatic islets of Langerhans with few irregular interlobular ducts; (F) kidney of glibenclamide-treated rat showing mild vascular degeneration of tubules and acute patchy haemorrhagic congestion; (G) liver of methanolic extract of Cinnamomum zeylanicum $500 \mathrm{mg} / \mathrm{kg}$-treated rat showing degeneration of hepatocytes and mortaled speckled appearance of the cytoplasm with the nuclei intact; $(\mathrm{H})$ pancreas of methanolic extract of Cinnamomum zeylanicum 500 $\mathrm{mg} / \mathrm{kg}$-treated rat showing no apparent degeneration changes of pancreatic acini; and (I) kidney of methanolic extract of Cinnamomum zeylanicum $500 \mathrm{mg} / \mathrm{kg}$-treated rat showing regenerative tubules and interstitial congestion. 


\section{DISCUSSION}

MECZ has rich total phenolic and total flavanoid content and showed the presence of antioxidant activity. Hence, MECZ was used for pharmacological studies. The total phenolic substances and flavonoids are the most important bioactive constituents of plants and may have vast potential to be an important source of phytomedicine. ${ }^{18}$

In the present study, the various solvent extracts of C. zeylanicum were tested for their free radical scavenging activity and concentration-dependent radical scavenging activity was observed in DPPH and ABTS methods. The various solvent extracts of $C$. zeylanicum were also showed the presence of total phenolics and flavonoids contents and this phytochemical may be responsible for its antioxidant activity. The flavonoids and phenolic compounds are the natural antioxidants that neutralizes the deleterious action of reactive species by hydrogen atom transfer, electron transfer and the ability to chelate transition metals. ${ }^{19}$

Streptozotocin, also known as streptozocin is a glucosamine nitrosourea compound derived from a gram-positive bacterium (Streptomyces achromogenes) and is toxic to the insulin-producing beta cells of the pancreas in mammals. The damage caused to the pancreatic beta cells is severe to a stage where repair is impossible in most cases. ${ }^{20}$

Diabetic animals exhibited a loss in body weight and diabetic animals treated with glibenclamide and MECZ prevented weight loss as well as to regulate the blood glucose level primarily. This finding suggests C. zeylanicum has the ability and beneficial aspects in regulating the body weight as well as controlling hyperglycemia of diabetic rats. Severe weight loss occurred in diabetes mellitus rats due to the increased muscle breakdown which is part of the characterization of STZ-induced diabetes mellitus. ${ }^{21}$

The MECZ is showing the significant antidiabetic activity and this effect was comparable with glibenclamide. The constituents present in the plant species, individually or synergistically, is the contributing factor of the antidiabetic activity. ${ }^{22}$ The presence of phytoconstituents such as alkaloids, terpenoids, glycosides, flavonoids are possess antioxidant activity and contribute to the antidiabetic activity. The phytochemical constituents of C. zeylanicum are cinnamaldehyde, eugenol, trans-cinnamyl acetate, trans-caryophyllene, linalool, eugenol acetate, isoeugenol, benzyl benzoate, $\alpha$ pinene, $\beta$ pinene, $\beta$ caryophyllene, $p$-cymene, camphor and cinnamyl acetate. ${ }^{23}$ In that, the antidiabetic activity of cinnamaldehyde, linalool and $\beta$ caryophyllene was explored by the various researchers. Plaisier et al. repeated the antidiabetic activity of cinnamaldehyde and this activity may be due to inhibition of the activation of glucose uptake by glucose deprivation in a dose-dependent manner. ${ }^{24}$ Cinnamaldehyde also, increased plasma insulin, hepatic glycogen and HDL levels and restored the altered hepatic enzyme levels. ${ }^{25}$ In both in vitro and in vivo studies, linalool showed antidiabetic activity and enhances insulin resistance. ${ }^{26}$ In a preclinical study, the diabetic rats treated with $\beta$ caryophyllene for 45 days showed significant decreases in the levels of glucose with increased plasma insulin levels and ameliorated the altered activities of carbohydrate metabolic enzymes. ${ }^{27}$ Cinnamon has the ability to enhance insulin signaling by potentiating insulin-regulated glucose utilization. ${ }^{28}$ The hypoglycemic effect of cinnamon is may be due to the increase of the pancreatic secretion of insulin from the beta cells. ${ }^{29}$

In the biochemical analysis, the animals treated with glibenclamide showed significant increases in the levels of creatinine and MECZ (125 and $250 \mathrm{mg} / \mathrm{kg}$ ) showed decreases in the levels of urea. Kidney function is assessed by determining the levels of creatinine, urea, uric acid and electrolytes. Creatinine is a metabolic by-product and its concentration is increased in the blood indicating kidney dysfunction. ${ }^{30}$ The diabetic animals showed increases in the level of creatinine, but the values are not significant. In general, STZ increases the levels of SGOT, SGPT, ALP, urea and creatinine. ${ }^{31}$ Glibenclamide is had antioxidant properties and has the hepatoprotective and neuroprotective effects that are mediated through upregulation of intracellular reactive oxygen species and inhibit of apoptosis pathway, respectively. ${ }^{32,33}$ Diabetic animals showed increases in the levels of serum sodium levels that indicating the risk of development of renal failure. ${ }^{34}$ The animals treated with MECZ, showed a significant reduction in serum sodium level compared with diabetic animals, which indicates that this plant has a nephroprotective effect. Ullah et al. reported the nephroprotective effect of $C$. zeylanicum. ${ }^{35}$ The reason for significant reduction of urea levels in MECZ is not clear. Postprandial hyperlipidemia observed in diabetic animals and this indicating that diabetic animals having a risk of developing cardiovascular disease. ${ }^{36}$ Glibenclamide and MECZ prevented STZ-induced postprandial hyperlipidemia, indicating that the investigational compound reducing the risk of development of the cardiovascular disease.

The reduction in insulin levels in the diabetic control group is due to the increased heme oxygenase activity in the liver of rats. ${ }^{37}$ Furthermore, damage to the $\beta$-cells in the pancreas may lower the insulin levels compared with the normal control group. The rats treated with glibenclamide and MECZ try to restore the insulin levels, but the results were not significant.

Histopathology of the liver, pancreas and kidney of diabetic animals showed moderate-to-severe toxic effects and this may be due to degeneration of hepatocytes, intracellular changes in pancreatic cells and degeneration of the tubular epithelial cells respectively. The cellular damage in the liver, pancreas and kidney induced by STZ also reported elsewhere. $^{38,39}$ The animals treated with glibenclamide and MECC reversed the STZ-induced cellular damage.

In a clinical trial, water extract of C. zeylanicum significantly reduced the systolic \& diastolic blood pressure and reduced the levels of TC \& LDL. ${ }^{40}$ Ranjbar et al. studied the antioxidative stress potential of C. zeylanicum in humans and found that decease in the levels of lipid peroxidation and increase in total antioxidant power in individuals who received cinnamon tea (100 mg/30 ml of cinnamon with tea daily for two weeks) compare to those who receive regular tea. ${ }^{41}$

\section{CONCLUSION}

Methanolic extract of C. zeylanicum has an ameliorative effect on STZinduced diabetic's mellitus and this effect may be through its antioxidant defense mechanism. Methanolic extract of C. zeylanicum prevents the cellar damage in the liver, pancreas and kidney of STZ- induced diabetic rats. In addition, the methanolic extract of C. zeylanicum has stimulated insulin secretion from the pancreatic islets of the diabetic rat.

\section{CONFLICT OF INTEREST}

The authors declare no Conflict of interest.

\section{ABBREVIATIONS}

ABTS: 2,2-azino-bis-3-ethylbenzothiazoline-6-sulfonic acid; ALP: Alkaline phosphatase; ANOVA: Analysis of variance; CMC: Carboxymethyl cellulose; DPPH: 2,2-diphenyl-1-picrylhydrazyl; ELISA: Enzyme-linked immunosorbent assay; GAE: Gallic acid equivalents; $\mathbf{H}$ and E: Haemotoxylin and Eosin; HDL: High-density lipoprotein; LDL: Low-density lipoprotein; MECZ: Methanolic extract of Cinnamomum zeylanicum; OECD: Organisation for Economic Co-operation and Development; QE: Quercetin equivalents; SD: Sprague-Dawley; SEM: Standard error of the mean; SGOT: Serum glutamic oxaloacetic transaminase; SGPT: Serum glutamic-pyruvic transaminase; STZ: Streptozotocin; UV-vis: Ultraviolet-visible; VLDL: Very low-density lipoprotein. 


\section{REFERENCES}

1. Sen $S$, Chakraborty R, De B, Devanna N. An ethnobotanical survey of medicinal plants used by ethnic people in West and South district of Tripura, India. J For Res. 2011;22(3):417-36.

2. Cragg GM, Newman DJ. Plants as a source of anti-cancer agents. J Ethnopharmacol. 2005;100(1-2):72-9.

3. Mukherjee PK, Kenerley CM. Regulation of morphogenesis and biocontro properties in Trichoderma virens by a VELVET protein, Vel1. Appl Environ Microbiol. 2010;76(7):2345-52

4. Paranagama PA, Wimalasena S, Jayatilake GS, Jayawardena AL, Senanayake UM, Mubarak AM. A comparison of essential oil constituents of bark, leaf root and fruit of cinnamon (Cinnamomum zeylanicum Blum), grown in Sri Lanka. J Natl Sci Found Sri. 2010;29:147-53.

5. Wiart C. Medicinal plants of Asia and Pacific. $1^{\text {st }}$ ed. CRC Press.2006.

6. Semwal DE, Semwal RB. Ethnobotany, Pharmacology and Phytochemistry of the Genus phoebe (Lauraceae). Mini Rev Org Chem. 2013;10(1):12-26.

7. Simić A, Soković MD, Ristić M, Grujić-Jovanović S, Vukojević J, Marin PD. The chemical composition of some lauraceaeessential oils and their antifunga activities. Phytother Res. 2004;18(9):713-7.

8. Chericoni S, Prieto JM, lacopini P, Cioni P, Morelli I. In vitro activity of the essential oil of Cinnamomum zeylanicum and eugenol in peroxynitrite-induced oxidative processes. J Agric Food Chem. 2005;53(12):4762-5.

9. Mesripour A, Moghimi F, Rafieian-Kopaie M. The effect of Cinnamomum zeylanicum bark water extract on memory performance in alloxan-induced diabetic mice. Res Pharm Sci. 2016;11(4):318-23.

10. Chandel M, Kaur S, Kumar S. Studies on the genoprotective/antioxidant potential of methanol extract of Anthocephalus cadamba (Roxb.) Miq. J Med Plants Res. 2011;5(19):4764-70.

11. Pochapski MT, Fosquiera EC, Esmerino LA, Dos SEB, Farago PV, Santos FA, et al. Phytochemical screening, antioxidant and antimicrobial activities of the crude leaves' extract from Ipomoea batatas (L.) Lam. Pharmacogn Mag 2011;7(26):165-70

12. Sen S, De B, Devanna N, Chakraborty R. Total phenolic, total flavonoid content and antioxidant capacity of the leaves of Meyna spinosa Roxb. An Indian medicinal plant. Chin J Nat Med. 2013;11(2):149-57.

13. Olugbami JO, Gbadegesin MA, Odunola OA. In vitro free radical scavenging and antioxidant properties of ethanol extract of Terminalia glaucescens. Pharmacognosy Res. 2015;7(1):49-56.

14. Stanojević LP, Cakić MD, Stanojević JS, Cvetković DJ, Danilović BR. Aqueous Extract of Wild Cyclamen Tubers (Cyclamen Purpurascens L.)-A Potential Source of Natural Antioxidants and Antimicrobial Agents. Quality Life. 2018;16(1-2):139.

15. Acute oral toxicity-Acute toxic class method. OECD Guideline for testing of chemicals 432. 2001;1-14 Available in https://ntp.niehs.nih.gov/iccvam/ suppdocs/feddocs/oecd/oecd_gl423.pdf [Last assessed on 06-04-2020]

16. Singh J, Parasuraman S, Kathiresan S. Antioxidant and antidiabetic activities of methanolic extract of Cinnamomum cassia. Phcog Res. 2018;10(3):237-42.

17. Petchi RR, Parasuraman S, Vijaya C. Antidiabetic and antihyperlipidemic effects of an ethanolic extract of the whole plant of Tridax procumbens (Linn.) in streptozotocin-induced diabetic rats. J Basic Clin Pharm. 2013;4(4):88-92.

18. Baron M, Kumsta M, Prusova B, Tomaskova L, Sochor J. Effect of prefermentation maceration on the content of antioxidant compounds in grapevine juice. Notulae Botanicae Horti Agrobotanici Cluj-Napoca. 2017;45(1):105-11.

19. Granato D, Shahidi F, Wrolstad R, Kilmartin P, Melton LD, Hidalgo FJ, et al. Antioxidant activity, total phenolics and flavonoids contents: Should we ban in vitro screening methods?. Food Chemistry. 2018;264:471-5.

20. Graham KL, Krishnamurthy B, Fynch S, Mollah ZU, Slattery R, Santamaria P, et al. Autoreactive cytotoxic T Iymphocytes acquire higher expression of cytotoxic effector markers in the islets of NOD mice after priming in pancreatic lymph nodes. Am J Pathol. 2011;178(6):2716-25.

21. Baynes JW, Thorpe SR. Role of oxidative stress in diabetic complications: A new perspective on an old paradigm. Diabetes. 1999;48(1):1-9.

22. Pareek H, Sharma S, Khajja BS, Jain K, Jain GC. Evaluation of hypoglycemic and anti-hyperglycemic potential of Tridax procumbens (Linn.). BMC Complement Altern Med. 2009;9(1):48

23. Dalai MK, Bhadra S, Chaudhary SK, Chanda J, Bandyopadhyay A, Mukherjee
PK. Anticholinesterase activity of Cinnamomum zeylanicum L. leaf extract. Tang. 2014;4(2):21-6.

24. Plaisier C, Cok A, Scott J, Opejin A, Bushhouse KT, Salie MJ, et al. Effects of cinnamaldehyde on the glucose transport activity of GLUT1. Biochimie. 2011;93(2):339-44.

25. Babu PS, Prabuseenivasan S, Ignacimuthu S. Cinnamaldehyde-a potential antidiabetic agent. Phytomedicine. 2007;14(1):15-22.

26. More TA, Kulkarni BR, Nalawade ML, Arvindekar AU. Antidiabetic activity of linalool and limonene in streptozotocin-induced diabetic rat: A combinatorial therapy approach. Int J Pharm Pharm Sci. 2014;6(8):159-63.

27. Basha RH, Sankaranarayanan C. $\beta$-Caryophyllene, a natural sesquiterpene, modulates carbohydrate metabolism in streptozotocin-induced diabetic rats Acta Histochemica. 2014;116(8):1469-79.

28. Imparl-Radosevich J, Deas S, Polansky MM, Baedke DA, Ingebritsen TS Anderson RA, et al. Regulation of PTP-1 and insulin receptor kinase by fractions from cinnamon: Implications for cinnamon regulation of insulin signalling. Horm Res Paediatr. 1998;50(3):177-82

29. Cheng DM, Kuhn P, Poulev A, Rojo LE, Lila MA, Raskin I. In vivo and in vitro antidiabetic effects of aqueous cinnamon extract and cinnamon polyphenolenhanced food matrix. Food Chem. 2012;135(4):2994-3002.

30. Sreejesh PG, Thampi BH, Sreekumaran E. Hypoglycaemic effect of glibenclamide: A critical study on the basis of creatinine and lipid peroxidation status of streptozotocin-induced diabetic rat. Indian J Pharm Sci. 2017;79(5):76877.

31. Tchamgoue AD, Tchokouaha LR, Tsabang N, Tarkang PA, Kuiate JR, Agbor GA. Costus afer protects cardio-, hepato- and reno-antioxidant status in streptozotocin-intoxicated wistar rats. BioMed Res Int. 2018.

32. Zhou F, Liu Y, Yang B, Hu Z. Neuroprotective potential of glibenclamide is mediated by antioxidant and anti-apoptotic pathways in intracerebra hemorrhage. Brain Res Bull. 2018;142:18-24.

33. Liu H, Wang S, Wu Z, Huang Z, You CW, Yang Y, et al. Glibenclamide, a diabetic drug, prevents acute radiation-induced liver injury of mice via up-regulating intracellular ROS and subsequently activating Akt-NF-kB pathway. Oncotarget. 2017:8(25):40568

34. Kuwabara M, Hisatome I, Roncal-Jimenez CA, Niwa K, Andres-Hernando A, Jensen $T$, et al. Increased serum sodium and serum osmolarity are independent risk factors for developing chronic kidney disease; 5 year cohort study. PLoS One. 2017;12(1):1-14.

35. Ullah N, Khan MA, Khan S, Khan A, Ahmad W. Nephroprotective property of Cinnamomum zeylanicum and its antibacterial activity in combination with gantamicin. Pak J Pharm Sci. 2017;30(1):55-60.

36. Kusunoki J, Aragane K, Kitamine T, Kozono H, Kano K, Fujinami K, et al. Postprandial hyperlipidemia in streptozotocin-induced diabetic rats is due to abnormal increase in intestinal acyl coenzyme A: Cholesterol acyltransferase activity. Arterioscler Thromb Vasc Biol. 2000;20(1):171-8.

37. Solangi K, Sacerdoti D, Goodman Al, Schwartzman ML, Abraham NG, Levere RD. Differential effects of partial hepatectomy on hepatic and renal heme and cytochrome P450 metabolism. Am J Med Sci. 1988;296(6):387-91.

38. Ebrahimi E, Kheirollah A, Mansouri E, Babaahmadi-Rezaei H, Mohammadzadeh G. Effects of Hydroalcoholic Flower Extract of Marigold (Calendula officinalis) on the Biochemical and Histological Parameters in STZ-Induced Diabetic Rats. Jundishapur J Nat Pharm Prod. 2019;14(3):e55456.

39. Balakrishnan BB, Krishnasamy K, Mayakrishnan V, Selvaraj A. Moringa concanensis Nimmo extracts ameliorates hyperglycemia-mediated oxidative stress and upregulates PPARy and GLUT4 gene expression in liver and pancreas of streptozotocin-nicotinamide induced diabetic rats. Biomedicine and Pharmacotherapy. 2019;112:108688.

40. Ranasinghe $P$, Jayawardena R, Pigera S, Wathurapatha WS, Weeratunga HD, Premakumara GAS, et al. Evaluation of pharmacodynamic properties and safety of Cinnamomum zeylanicum (Ceylon cinnamon) in healthy adults: A phase I clinical trial. BMC Complement Altern Med. 2017;17(1):550.

41. Ranjbar A, Ghasmeinezhad S, Zamani H, Malekirad AA, Baiaty A, Mohammadirad $A$, et al. Antioxidative stress potential of Cinnamomum zeylanicum in humans: A comparative cross-sectional clinical study. Clin Pract. 2006:3(1):113-7. 


\section{GRAPHICAL ABSTRACT}

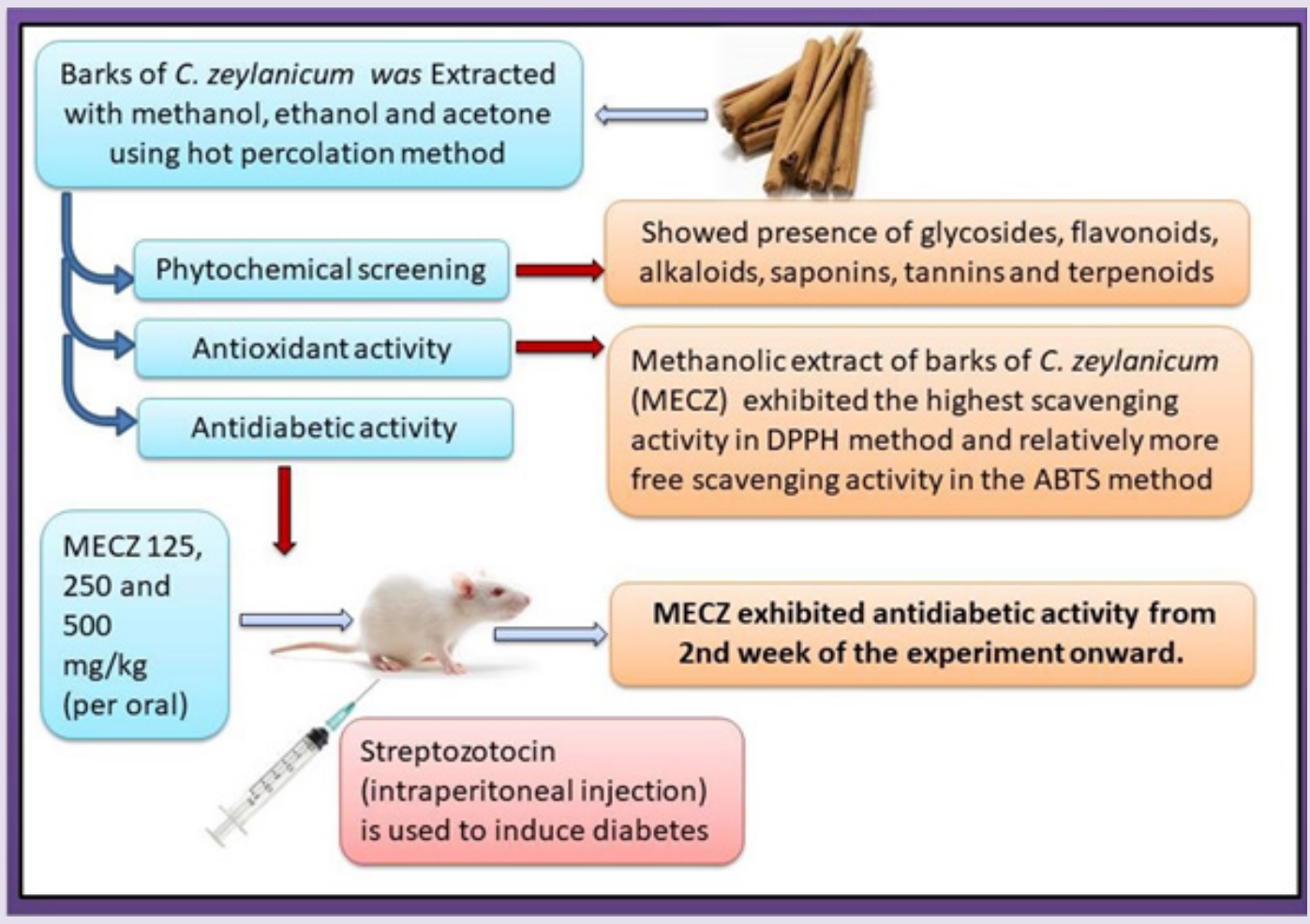

\section{SUMMARY}

- Cinnamomum zeylanicum is one of the well-known plant species for its medicinal properties.

- Methanolic, ethanol and acetone extract of Cinnamomum zeylanicum exhibited free radical scavenging properties.

- Methanolic extract of Bark of Cinnamomum zeylanicum prevented streptozotocin-induced diabetes mellitus in rats.

\section{ABOUT AUTHORS}

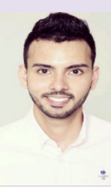

Rasvin Singh is obtained his 'Master of Science in Biotechnology' degree from AIMST University, Malaysia. Currently, he is working as Production Associate with Biocon Malaysia. He handles the process of purification of proteins for the production of Human Insulin.

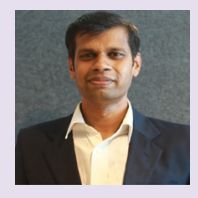

Dr. Subramani Parasuraman is a Associate Professor \& Head, Department of Pharmacology, Faculty of Pharmacy, AIMST University, Malaysia. His research interest is in the areas of pre-clinical pharmacodynamics and toxicological studies.

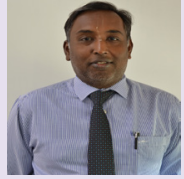

Dr. S. Kathiresan has completed his B.App.Sc (Hons), M.Sc and Ph.D from Universiti Sains Malaysia and has over 20 years of working is both industry and academia. He has been involved in numerous researches particularly in the area of conversion of waste into wealth and sustainability studies. His expertise is in the field of chromatography, spectroscopy and thermal analysis. He is currently a consultant to several companies in the northern region.

At present Dr. S. Kathiresan is the Registrar and the Commander, Malaysian Civil Service Department at AIMST with an Honorary Colonel Rank. Here he is has to provide overall leadership to the operations of the University. $\mathrm{He}$ is well experienced in developing strategic planning for organizations particularly academia.

Dr. Kathiresan is currently the Honorary Secretary for Institut Kimia Malaysia (Northern Branch).

Cite this article: Singh R, Parasuraman S, Kathiresan S. Antioxidant and Antidiabetic Activity of Methanolic extract of Bark of Cinnamomum zeylanicum in Diabetic Rats. Free Radicals and Antioxidants. 2020;10(1):16-23. 